\title{
Enfoque CTS e ensino: relatos do reitor da Universidad Nacional Pedagógica, Prof. Dr. Leonardo Fábio Martinez Pérez
}

Rosemari Monteiro Castilho Foggiatto Silveira rosemari@utfpr.edu.br 0000-0002-0432-5182

Universidade Tecnológica Federal do Paraná, Ponta Grossa, Paraná, Brasil.

Hércules Alves de Oliveira Junior hercules@utfpr.edu.br

0000-0002-1760-7621

Universidade Tecnológica Federal do

Paraná, Ponta Grossa, Paraná, Brasil.

\section{RESUMO}

Em entrevista concedida à RBECT o reitor da Universidad Nacional Pedagógica de Bogotá na Colômbia, Prof. Dr. Leonardo Fábio Martinez Pérez apresenta sua trajetória como professor, o trabalho realizado frente a reitoria da instituição e possibilidades de inclusão da abordagem CTS na formação de professores dentro deste contexto. Na entrevista, o professor também destaca as ações e processos de ensino vivenciados na instituição no atual momento de pandemia e isolamento social, permitindo-nos conhecer um pouco sobre o cenário e práticas colombianas.
\end{abstract}

PALAVRAS-CHAVE: Educação superior. Ensino. Enfoque CTS. 


\section{APRESENTAÇÃO}

O Professor Doutor Leonardo Fábio Martinez Pérez possui graduação em Licenciatura em Química e Mestrado em Docência da Química pela Universidad Pedagógica Nacional - Colômbia. É Doutor em Educação para a Ciência pela Universidade Estadual Paulista Júlio de Mesquita Filho; Brasil. Atualmente é Reitor da Universidade Pedagógica Nacional da Colômbia. Atua como professor dos cursos de Licenciatura em Química, Mestrado em Docência da Química e Doutorado em Educação da mesma universidade. Durante os anos 2015 e 2016 foi editor da Revista Tecné, Episteme e Didaxis. É fundador do grupo de pesquisa denominado como Alternativas para o Ensino de Ciências. Possui publicações no contexto colombiano e no contexto internacional sobre o Ensino de Ciências com enfoque ciência, tecnologia, sociedade e ambiente, questões sociocientificas na prática do professor, Ensino de Química, Formação de professores, epistemologia das ciências, argumentação e desenvolvimento de pensamento crítico no Ensino de Ciências.

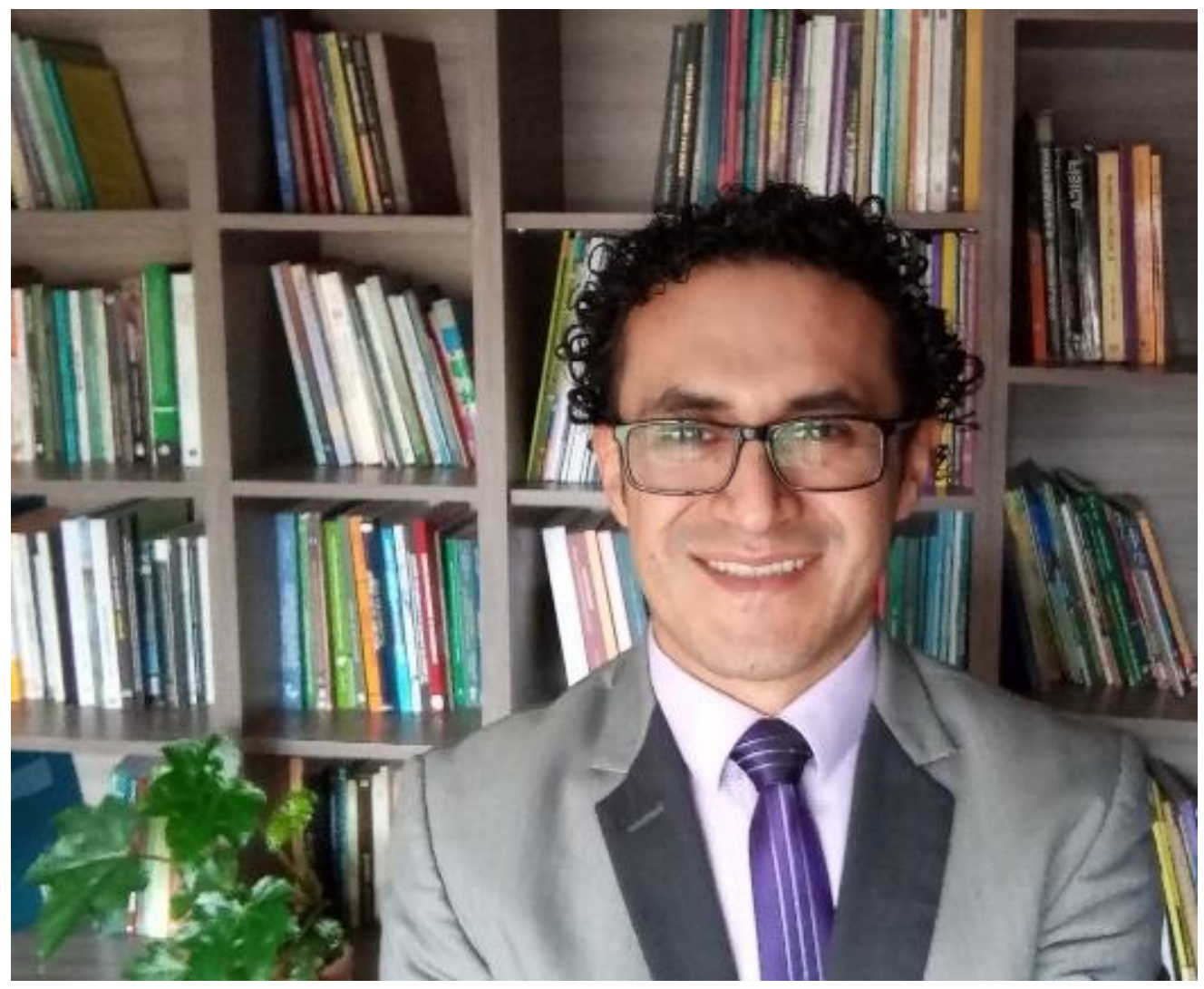

Leonardo Fábio Martinez Pérez, reitor da Universidad Pedagógica Nacional (Foto: Acervo pessoal) 


\section{ENTREVISTA}

\section{Iniciando nossa entrevista gostaria de perguntar como e quando percebeu o seu interesse pelo ensino?}

Neste momento fico pensando quando nasceu essa vontade de ser professor, de ensinar a outras pessoas coisas interessantes. Na verdade, quando terminei meu Ensino Médio em 1996 tinha vontade de ser médico e concorri as provas para o ingresso na Universidade Nacional da Colômbia, mas não deu certo, no mesmo momento concorri para a Licenciatura em Química na Universidade Pedagógica Nacional e para a Licenciatura em Biologia na Universidade Distrital, os dois cursos orientados à formação de professores, mas meu interesse era pela Química e a Biologia, áreas básicas para a medicina.

Escolhi a Licenciatura em Química por causa de estar na melhor universidade pública focada exclusivamente na formação de professores, mais ainda não era claro se eu seria professor, pois continuei tentando o ingresso ao curso de medicina. Depois de uns anos no curso de licenciatura e especialmente durante meu estagio supervisionado de prática de ensino, ficou claro que a minha grande paixão era o ensino das ciências da natureza em geral e em particular da Química, pois ensinei conceitos de ciência para as crianças de ensino fundamental, foi muito legal trabalhar com elas, trabalhar sobre problemas de seu contexto social e natural.

Trabalhei com crianças carentes que moravam na periferia da cidade de Bogotá por causa de deslocamentos gerados por grupos armados, deslocados pela violência que vive o nosso país. Depois de meu estagio continuei trabalhando com a mesma população e fiz meu trabalho de conclusão de curso de graduação sobre uma proposta para ensinar ciências baseada da pedagogia crítica. Penso que foi no estágio e na pesquisa que ficou claro meu projeto de vida como professor. Hoje penso que quando estava na última série de ensino médio tive a oportunidade de fazer um estágio com crianças da sexta série sobre Educação Física e talvez, tenha sido nessa oportunidade que nasceu inconscientemente a vontade de ser professor, pois sempre lembro essa experiência com alegria e carinho, pois passei muito bem ensinando atividades esportivas na quadra da escola, depois na faculdade me tornei professor de ciências mesmo.

O senhor tem se dedicado a trabalhar as questões CTS com seus alunos, como é trabalhar essas questões na formação de docentes e qual a receptividade pela temática? Como faz para instigar seus alunos a perceberem as questões CTS no ensino e como eles devem usá-las?

Na realização do meu trabalho de conclusão de curso de graduação no 2001, não tinha claro o referencial CTS, no entanto, nessa oportunidade penso que desenvolvi um ensino CTS, pois a proposta abrangeu o ensino de propriedades e mudanças de matérias do entorno natural e contexto social das crianças, então sem saber estava articulando relações entre a ciência e a sociedade. Desde o ano de 2003 trabalho conscientemente com o referencial CTSA, o primeiro trabalho foi com licenciandos que participavam de uma disciplina de Bioquímica, nessa ocasião foi mais relevante o aprendizado de conceitos de bioquímica relacionados 
como o metabolismo das plantas, a partir deste de trabalho de pesquisa desenvolvo aulas de química e ciências baseado na abordagem CTSA, evidenciou maior interesse pelo estudo de conceitos científicos, uma melhor atitude para aprendizagem e uma melhor compreensão da natureza da ciência e da tecnologia, esses resultados e experiências também são bem sucedidos no trabalho que é feito com professores em serviço.

Atualmente trabalho as relações CTSA a partir da abordagem de questões sociocientíficas, o primeiro que faço é caracterizar interesses dos licenciandos e suas concepções sobre ciência e tecnologia, a partir disto procuro a escolha de uma questão sociocientífica (QSC) relevante, por exemplo, tenho trabalhado a geração de energia a partir de biocombustíveis, transgênicos, clonagem, automedicação, uso de pílula do dia depois, entre outras. A partir da QSC escolhida estruturo sequências de ensino para favorecer a argumentação, a tomada de decisão ou o desenvolvimento do pensamento crítico. De todo este trabalho tenho conseguido bons resultados com os estudantes em termos de uma melhor compreensão da ciência e da tecnologia, argumentação e desenvolvimento de pensamento crítico.

\section{O senhor acha que se está conseguindo levar essa discussão para a sala de aula do ensino básico?}

Nos últimos 17 anos tenho me dedicado a formação de professores e nesse sentido somente através das pesquisas que desenvolvo junto com esses professores tenho conseguido a análise da abordagem CTSA no ensino básico. Baseado nessas experiências posso dizer que é possível trabalhar CTSA no ensino básico para potencializar a curiosidade e o interesse pelas ciências, através de projetos escolares é possível fazer isso com estudo de casos concretos sobre problemas ambientais de seu entorno.

Em sua opinião, os seus alunos de graduação, no exercício de sua profissão docente tem trabalhado com o enfoque CTS?

Eu tenho feito trabalhos de pesquisas com Professores em serviço sobre a abordagem de questões sociocientífica e nesse sentido eles trabalham nessas relações CTSA, tenho procurado investigar o êxito, e analisar os projetos de ensino de Professores sobre, e, essa, essa abordagem no ensino é, fundamental mas nas séries 6ạ e tipo, série 7ạ , 8aㅗ série, e mas nas primeiras séries não, não tenho esses trabalhos, mas poderia sim explorar, é, se a Senhora conhecer a minha tese de doutorado faço uma análise de projeto de pesquisa dos Professores, então têm vários que fizeram trabalho sobre CTS já, e a sua abordagem em séries no Ensino Fundamental mas não nas primeiras não.

O senhor tem se dedicado a trabalhar mais na a formação de professores em como eles ensinam, ou com os alunos nas questões de aprendizagem?

Tenho me dedicado mais a formação de professores sobre CTSA e na minha própria prática de ensino trabalho essa perspectiva com licenciandos em aulas de química e didática. 
A aplicação de questões CTS no Brasil ainda estão em crescimento, especialmente devido ao surgimento de diversas pós-graduações em ensino. Como isso ocorre na Colômbia?

Na Colômbia os trabalhos começaram a serem publicados no final da década de 1990 e nos últimos 20 anos tem evoluído, mais ainda há poucos trabalhos em ensino básico, existem mais trabalhos em ensino médio e na formação de professores. Ainda estamos longe de conseguir que CTSA seja uma perspectiva que orienta a construção de currículos no país e faça parte das orientações curriculares nacionais.

Para efeitos de conhecer revisões sobre o tema na Colômbia se sugere a leitura dos textos anexos.

Na Colômbia também existem programas de mestrado específicos para o ensino, como existem no Brasil (como os de Química, Física e Matemática)?

Na Colômbia somente existe um mestrado em Ensino de Química oferecido pela Universidad Pedagógica Nacional, existe mestrados em ensino de ciências e doutorados em educação os quais abrangem a área de ensino de ciências.

\section{Como foi sua experiência no Brasil quanto à sua formação?}

Foi fundamental para o aprofundamento de referenciais teóricos e metodológicos para desenvolver pesquisa em ensino de ciências, especialmente aprendi muito sobre o referencial de Paulo Freire, teoria crítica e análise crítica de discurso.

Atualmente o senhor está à frente como Reitor da Universidade Pedagógica Nacional da Colômbia. Como a Universidade, seus acadêmicos e professores vêm se mobilizando para desenvolverem as atividades Universitárias neste momento de pandemia da COVID19?

A nossa universidade tem encarado a pandemia com um conjunto de ações focadas em manter o funcionamento dos processos de docência, pesquisa e extensão, sempre procurando apoiar aos alunos de graduação que fazem parte de setores carentes da sociedade, nos seguintes links podem revisar as diferentes ações que o professor tem desenvolvido:

http://www.pedagogica.edu.co/home/vernoticia/1093

http://www.pedagogica.edu.co/home/vernoticia/1199

https://www.youtube.com/watch?v=MgHeF1sq80M\&list=PLzpfjFwUBmP7UFhm u BcNPCEyXQtJn6YK\&index $=2$

https://www.youtube.com/watch?v=0SnVGVODWB8\&list=PLzpfjFwUBmP7UFhm u BcNPCEyXQtJn6YK\&index $=34$

https://www.youtube.com/watch?v=ZBAulQu- 
https://www.youtube.com/watch?v=CT4q9s2fZ5M\&list=PLzpfjFwUBmP7UFhmu BcNPCEyXQtJn6YK\&index $=24$

https://www.youtube.com/watch?v=ERo1MtBjf0\&list=PLzpfjFwUBmP7UFhmu BcNPCEyXQtJn6YK\&index $=11$

https://www.youtube.com/watch?v=kUmdl3EPAkQ\&list=PLzpfjFwUBmP7UFhmu BcNPCEyXQtJn6YK\&index $=12$

https://www.youtube.com/watch?v=YZb690oZ60\&list=PLzpfjFwUBmP7UFhmu BcNPCEYXQtJn6YK\&index $=25$ https://www.youtube.com/watch?v=pr3RIOf8Qd4\&list=PLzpfjFwUBmP7UFhmu BcNPCEyXQtJn6YK\&index $=15$

Vocês têm adotado o ensino de forma remota? Como o senhor vê o trabalho docente de forma remota?

Para a proteção da vida de toda a comunidade de nossa universidade, realizamos trabalho remoto e ensino a distância mediado por tecnologias da informação e da comunicação (TIC). O trabalho docente remoto tem grandes possibilidades para favorecer o trabalho autônomo dos estudantes com a orientação dos professores, no entanto, não substitui o trabalho de sala de aula, pois a interação real é fundamental para processos de interação social e o desenvolvimento de capacidades práticas que não podem ser atingidas como o uso de diferentes plataformas tecnológicas.

Já é possível pensar em um cenário pós-pandemia e suas implicações na formação e nas pesquisas acadêmicas?

Uma característica do mundo atual é a incerteza, com a pandemia é muito mais claro o fracasso das práticas de controle que o ser humano tem constituído sobre a natureza baseada numa racionalidade técnica. Neste sentido, ainda existe incerteza de como vai ser o mundo depois da pandemia e como vai impactar a formação e as pesquisas, o desejável é que possamos fazer mudanças nesses processos para conseguir construir uma melhor sociedade baseada em práticas sociais focadas na sustentabilidade. É necessário gerar uma nova educação um novo ensino para um novo mundo, se isso não acontece teremos desaproveitado uma oportunidade histórica.

Como o senhor avalia a educação na Colômbia e na América Latina, sobretudo sobre os recursos e incentivos ao desenvolvimento de pesquisas e estudos no Ensino Superior?

Nossos países ainda estão longe do investimento necessário para a educação e a pesquisa. Na Colômbia não existe gratuidade no ensino público superior e nesse sentido é necessária uma política pública que possibilite gratuidade no ensino público. $\mathrm{O}$ investimento em ciência é muito baixo. 
Que mensagem deixaria aos pesquisadores das mais diversas áreas da ciência que nos leem por meio da Revista Brasileira de Ensino de Ciência e Tecnologia?

Nós professores e pesquisadores do Ensino de Ciência temos uma grande responsabilidade na formação de cidadãos críticos e comprometidos com a análise do papel da ciência na sociedade, temos que favorecer uma melhor compreensão das relações CTSA para dessa forma desenvolver práticas e ações responsáveis da humanidade baseadas nos direitos humanos e no respeito da natureza. A crise social que vivemos, faz parte de uma crise ambiental que coloca em perigo a existência da vida no planeta e por essa razão é necessário contribuir com repensar o modelo de desenvolvimento social a partir do ensino de ciências. 


\title{
CTS APPROACH AND TEACHING: REPORTS BY THE UNIVERSIDAD NACIONAL PEDAGÓGICA' RECTOR, PROF. DR. LEONARDO FÁBIO MARTINEZ PÉREZ
}

\begin{abstract}
In an interview with RBECT, the rector of the Universidad Nacional Pedagógica de Bogotá in Colombia, Prof. Dr. Leonardo Fábio Martinez Pérez presents his trajectory as a teacher, the work in the institution's rectory and the inclusion possibilities the CTS approach in the training of teachers within this context. In the interview, the professor also highlights the actions and teaching processes experienced at the institution in the current moment of pandemic and social isolation, allowing us to know a little about the Colombian scenario and practices.
\end{abstract}

KEYWORDS: Higher education. Teaching. CTS approach. 
DOI: $10.3895 /$ rbect.v13n2.13070

Como citar: SILVEIRA, R. M. C. F.; JUNIOR, H. A. O. Enfoque CTS e ensino: relatos do reitor da

Universidad Nacional Pedagógica, Prof. Dr. Leonardo Fábio Martinez Pérez. Revista Brasileira de Ensino de Ciência e Tecnologia, Ponta Grossa, v.13, n. 2, p. 433-441, mai./ago. 2020. Disponível em:

<https://periodicos.utfpr.edu.br/rbect/article/view/13070>. Acesso em: XXX.

Correspondência: Rosemari Monteiro Castilho Foggiatto Silveira - rosemari@utfpr.edu.br

Direito autoral: Este artigo está licenciado sob os termos da Licença Creative Commons-Atribuição 4.0

Internacional.

(c) (i) 